\title{
Freiheit gilt innerhalb der ihr gesetzten Grenzen
}

\section{Jean Martin}

Ehemaliges Mitglied der Nationalen Ethikkommission, Mitglied der Redaktion

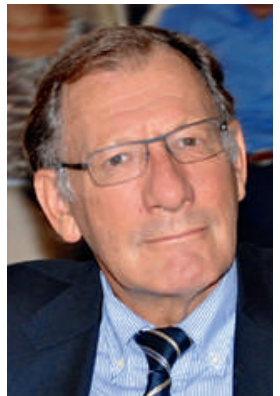

Vor kurzem war ich in den USA, ein Familienbesuch. Das Land ist durch den Tod des in Ferguson von einem Polizisten erschossenen jungen Schwarzen in Aufruhr geraten. Anfang März wurden dort der Polizei in einem offiziellen Bericht rassendiskriminierende Taten bescheinigt, der Polizeichef musste am 11. März zurücktreten. Zur gleichen Zeit schloss die Universität Oklahoma zwei Studenten aus. Auf einem Video war zu sehen, wie sie rassistische Lieder sangen, auch solche über die Zeiten von Segregation und Lynchjustiz. Im US-Alltag gibt es noch Rassismus. Dies verdeutlichen auch Zahlen, die manifest zeigen, wie unterschiedlich Gerichte mit Verbrechen umgehen, je nachdem, ob sie von einem Weissen oder Schwarzen verübt wurden. Glücklicherweise zeigen sich inzwischen Gegenreaktionen. Ausserdem herrscht eine bestimmte nostalgische, mit rassistischen Facetten versetzte Stimmung, die einher geht mit dem Widerstand der Republikaner («alt, weiss und männlich», sagt man) gegen jegliche Veränderungen im Lande, die mehr Gerechtigkeit, Vielfalt und multikulturelles Leben bewirken könnten und der aktuellen Realität entsprechen würden. Die extremen, rassistisch gefärbten, Angriffe, denen sich Präsident Obama und seine Gattin ausgesetzt sehen, lassen ernsthaft am Verstand einiger Politiker und Journalisten zweifeln.

Die der Universität Oklahoma verwiesenen Studenten haben aber ihre Unterstützer, die sich in von reichen Geldgebern gesponserten libertären Strömungen auf die verfassungsrechtlich geschützte Meinungsfreiheit berufen. Auch in der Schweiz wird die durch Volksabstimmung garantierte und in Art. 261bis unseres Strafgesetzbuchs verankerte Antirassismusklausel aus ähnlichen Motiven angegriffen. Nun birgt die ideologische Anrufung eines Rechts «alles tun und lassen zu können» eine Gefahr für unser Zusammenleben. Ich glaube an die Aussage «Freiheit gilt innerhalb der ihr gesetzten Grenzen", die anknüpft an die Aussage: «Freiheit endet da, wo die des anderen beginnt.» Wer wird abstreiten, dass das Respektieren des anderen für eine Gesellschaft ebenso zwingend sein sollte wie eine extreme Vorstellung von Freiheit?
An dieser Stelle ist man geneigt, an die schrecklichen Morde an den Journalisten von Charlie Hebdo zu erinnern. Solche Taten sind zu verdammen, und ich verdamme sie. Ich bin jedoch nicht damit einverstanden, dass dogmatisch ein absolutes Recht auf Beleidigung oder Blasphemie gefordert werden darf. Regelungen zur Ahndung von Verleumdungen und Diffamierungen gibt es seit langem. Ausserdem läuft eine Gesellschaft, die den religiösen Aspekt ignorieren oder gar eliminieren will, Gefahr, sich zu verschliessen, wie dies in Frankreich gegenwärtig in einem aggressiven, zwingend vorgegebenen Laizismus der Fall ist, wo auf jedes Auftreten religiösen Geschehens im öffentlichen Raum scharf reagiert wird. Eine Unnachgiebigkeit, die schon leicht an Borniertheit grenzt. Warum wird nicht erkannt, dass laizistische Bannsprüche für Worte oder Taten, die eigentlich nur (weder kämpferischer noch missionarischer) Ausdruck von Überzeugungen sind, die Freiheit verleugnen, die eigentlich verehrt wird? Das in der Schweiz geltende Prinzip der Neutralität staatlicher Stellen in religiösen Fragen ist da weitaus angemessener. Daher kann ein Zusammenleben gefördert werden, im Rahmen dessen der andere respektiert wird und seine Beweggründe verstanden werden. Dabei ist klar, dass Verstehen nicht beinhaltet, dass alles entschuldigt wird. Bestimmte Dinge sind strafbar und müssen bestraft werden!

Die Frage ist nun, was wir vorziehen: eine übertriebene Form der individuellen Freiheit oder ein Zusammenleben in gegenseitigem Respekt. Ich halte die erste Option für gefährlich. Sie wird wohl Quell unaufhörlicher Konflikte sein. Grundsätzliche Höflichkeit und Bürgersinn verlangen, dass wir klarstellen, dass die eigene Freiheit sicher nicht das Recht einräumt, den anderen, seine Glaubensvorstellungen, seine ethnischen Merkmale oder seine Herkunft nach Gutdünken zu beleidigen.

PS: Ebenfalls in diesem Kontext und künftig noch weiter zu thematisieren: «Libertäre» opponieren auch gegen eine vernünftige, altersgerechte Sexualaufklärung in der Schule, wie dies in der Schweiz bereits seit Jahrzehnten praktiziert wird. Auch dies hat diskriminierende Züge: Ein Teil der Kinder wird zu Hause nicht angemessen aufgeklärt, so wie dies erforderlich wäre. Wenn darüber nicht in der Schule gesprochen wird, sind sie in der Folge benachteiligt und anfälliger für Irrtümer und Negativfolgen. 